\title{
Efficacy of Doublesynch and Estra Doublesynch on Conception Rate of Cyclic Non breeding Cattle
}

\author{
P.P. Harichandan ${ }^{1 *}$, A.K. Barik ${ }^{1}$, P.C. Mishra ${ }^{1}$, B.K. Patra ${ }^{1}$, B. Jena ${ }^{1}$, \\ S.K. Mishra ${ }^{2}$ and A.K. Kundu ${ }^{3}$ \\ ${ }^{I}$ Department of Animal Reproduction, Gynaecology and Obstetrics, CVSc \& AH, OUAT, \\ Bhubaneswar, Odisha-751003, India \\ ${ }^{2}$ Department of Animal Nutrition, ${ }^{3}$ Department of Animal Physiology, CVSc \& AH, OUAT, \\ Bhubaneswar, Odisha-751003, India \\ *Corresponding author
}

\section{A B S T R A C T}

The objective of this study was to compare the conception rate for fixed-timed artificial insemination (FTAI) and observed heat artificial insemination (HAI) prior to the scheduled FTAI in Doublesynch and Estra doublesynch synchronization protocols as well as HAI in mineral supplemented cyclic non breeding cattles (RB). A total of 80 animals (40 RB

Keywords

Hormone,

Doublesynch, Estra

doublesynch,

Reproduction,

Repeat breeding

Article Info

Accepted:

10 March 2018

Available Online:

10 April 2018 cows, $40 \mathrm{RB}$ heifers) were selected and divided into four groups each constituting $20 \mathrm{RB}$ animals (10 heifers and 10 cows) in which different therapeutic regimen was followed along with supplementation of area specific mineral mixture (ASMM) for 60 days. Group I animals served as control which thrived on regular farmer practice. Group II animals were provided with only mineral supplementation (ASMM) for 60 days. Group III animals were provided with mineral supplementation along with the use of double synch protocol for estrous synchronization. Group IV animals were provided with mineral supplementation along with the use of Estra double synch protocol for estrous synchronization. Fixed time artificial insemination was performed in group III and IV whereas in group I and II, artificial insemination was done on observed estrus. Pregnancy diagnosis was done 45-60 days following artificial insemination by rectal palpation. Results revealed significant improvement in conception rate in treatment groups as compared to control group. The conception rate was highest in group IV (70\%) followed by group III (65\%), group II (40\%) and 15 percent in group I (control group). Comparison of different treatment protocol suggested that Estra doublesynch protocol fared better than other treatment schedule in establishment of pregnancy in repeat breeding cows and heifers.

\section{Introduction}

Repeat breeding $(\mathrm{RB})$ is one of the important causes of infertility in cattle that results in delayed conception and increased calving interval, loss of milk production, reduction in calf crop, increased cost of treatment and culling of useful breeding animals leading to heavy economic losses to the dairy producers (Lafi and Kaneene, 1992). In herds of normal fertility, where conception rates are commonly at $50-55 \%$, about $9-12 \%$ of the cows are 
expected to be repeat breeders. As the conception rate decreases, the number of cows requiring additional services increases. As a result, repeat breeding rapidly becomes a significant problem (Brunner, 1984). The hormonal changes and the increased nutrient demands for high production might negatively impact reproduction in dairy cows. Exhibition of oestrus and attainment of pregnancy is mainly controlled by hormonal status of the body. Hormonal imbalances are mainly categorized under pre-ovulatory and postovulatory phases. Subluteal levels of progesterone during the preovulatory period result in irregular, delayed or absent ovulation of dominant follicle. Insufficient corpus luteum at postovulatory period leads to low progesterone level and delayed progesterone rising leads to embryonic loss. Also, repeat breeding syndrome increases by insufficient estrus detection and errors of timing insemination (Keskin et al., 2010). To control all these problem hormonal treatment should be the last resort. Also in many organized farm hormones are used for routinely estrus synchronization, augmentation of fertility and post-partum reproductive management without any ill effect.

\section{Materials and Methods}

The present study was carried out in Dept. Of Animal Reproduction, Gynaecology and Obstetrics, CVSc \& AH, OUAT, Bhubaneswar. Healthy crossbred heifers and cows $\left(1^{\text {st }}\right.$ to $3^{\text {rd }}$ calver $)$ maintained under traditional husbandry practice with a history of repeat breeding in and around the urban and suburban areas of Bhubanewar as well as Niali block, Cuttack district were selected for the present investigation basing on the findings of per-rectal examination of reproductive tract. Clinical and sub-clinical genital infections were ruled out with a simple and rapid test known as White side test. A total of eighty crossbred animals free from any reproductive tract infection were considered for this study and assigned into four different groups. Each group constituted of $10 \mathrm{RB}$ heifers $(\mathrm{H})$ as well as $10 \mathrm{RB}$ cows (C). Group I animals served as control which thrived on regular farmer practice. Group II animals were provided with only mineral supplementation (Area Specific Mineral Mixture) for 60 days. Group III and IV animals were provided with mineral supplementation along with the use of doublesynch and estra doublesynch protocol respectively for estrous synchronization. FTAI was performed in animals subjected to synch protocols (group III and IV) whereas group I and II animals were inseminated on exhibited estrus. Pregnancy diagnosis done by per-rectal examination following 45-60 days of insemination.

In double synch protocol, $\mathrm{PGF}_{2} \alpha$ (Dinoprost tromethamine) and $\mathrm{GnRH}$ (Buserelin acetate) were used twice as shown in the figure in repeat breeder it is any day between 7-10 days of estrus. Fixed Time Artificial Insemination (FTAI) was conducted on 24 hours of last GnRH injection.

In Estra double synch protocol the steps taken were similar to double synch protocol with replacement of last $\mathrm{GnRH}$ injection with estradiol benzoate (Pregheat) in the above manner as shown in the figure. Fixed Time Artificial Insemination (FTAI) was adopted twice at 72 hours and 96 hours of last $\mathrm{PGF}_{2 \alpha}$ injection which is $48 \& 72$ hours of estradiol injection.

\section{Results and Discussion}

Conception rate of repeat breeding animals after various treatment protocols is presented in Table 1. In repeating heifers, conception rate was found to be 10, 40, 60 and 70 per cent for Groups I, II, III and IV respectively. In repeat breeder cows the conception rate was found to be 20,40, 70 and 70 per cent for 
Groups I, II, III and IV respectively. The overall conception rate was found to be 15 per cent in Group I (control group). Similarly, in Group II, III and IV, 40, 65 and 70 per cent animals were found to be pregnant after 45 60 days of AI, respectively.

The pregnancy percentage in Group II (40\%) was observed to be higher than that in control Group (15\%) which is in accordance with the findings of Das et al., (2016) who concluded that nutritional supplement improved the conception rate of crossbred cows with reproductive disorders by $35 \%$ than the control group (10\%). Mineral supplementation to crossbred cows improved the reproductive performance of repeat breeding cows and heifers. Devasena et al., (2010) studied the effect of supplementation of deficient minerals $(\mathrm{Ca}, \mathrm{P}, \mathrm{Cu}, \mathrm{Zn}$ and $\mathrm{Mn}$ ) through area specific mineral mixture (ASMM) for 90 days in crossbred cows having different reproductive disorders.

Among the animals under study, $60 \%$ of anoestrous cows, $62 \%$ of repeat breeder cows and $59 \%$ of anoestrous heifers responded to supplementation, indicating the beneficial effect of mineral supplementation on their reproductive performance. Mohapatra et al., (2012) observed that anoestrous heifers, anoestrous cows and repeat breeding cows supplemented with area specific mineral mixture (Ca, P, Zn, Cu, Mn, Co and I) @ 50 g/day/animal exhibited higher percent $(45,70$ and $60 \%$, respectively) of estrous compared to untreated cattle i.e. $10 \%$. The percentage conception was 5, 40, 40 and 35 in control, anoestrous heifers, anoestrous cows and repeat breeding cows, respectively. Services per conception and postpartum oestrous were significantly lower in the mineral supplemented groups than control. Thus, it was concluded that supplementation of area specific mineral mixture improved the reproductive performance.
The conception percentage of repeater cows in Group III was higher (65\%) than control (Group I) and mineral supplemented group (Group II) which is in accordance with the findings of Ozturk et al., (2010) who revealed that the Doublesynch method increased pregnancy rates by 43 percentage units $(29.8 \%$ vs. $72.8 \%, \mathrm{P}<0.0001)$ in relation to Ovsynch in both anestrous and cycling primiparous dairy cows. They opined that pregnancy rates of cows having small, medium, or large follicles at the day of second $\mathrm{GnRH}$ administration were similar in the Doublesynch group $(70.4 \%, 85.2 \%$, and $63.0 \%$, respectively; $\mathrm{P}>0.05)$, whereas pregnancy rates reduced dramatically as follicle size increased in the Ovsynch group. Cirit et al., (2007) developed doublesynch protocol by administering an additional $\mathrm{PGF}_{2} \alpha$ $48 \mathrm{hrs}$ before the ovsynch program which involved synchronized ovulation after both the first and second GnRH treatments.

Other studies have established that GnRH induced follicular turnover or induction of a new follicular wave is the most efficient if ovulation is induced in response to the first GnRH treatment (Thatcher et al., 1993) and that resetting the follicular development can produce a new dominant follicle containing an oocyte with greater potential fertility (Mihm et al., 1994). By using ovsynch protocol, Fricke et al., (1998) reported a pregnancy rate of 31 per cent, while Caraba and Velicevici (2013) got a higher rate of 57 per cent.

Keskin et al., (2010) reported that ovulatory response in repeat breeder cows and pregnancy rate was found to be greater when GnRH dose increased. The possible reason for variation could be the reproductive status or stage of estrous cycle at the beginning of the protocol, besides nutritional, managerial, lactation, drug source, age and breed and variations in geographical locations (Ramakrishnan et al., 2012). 


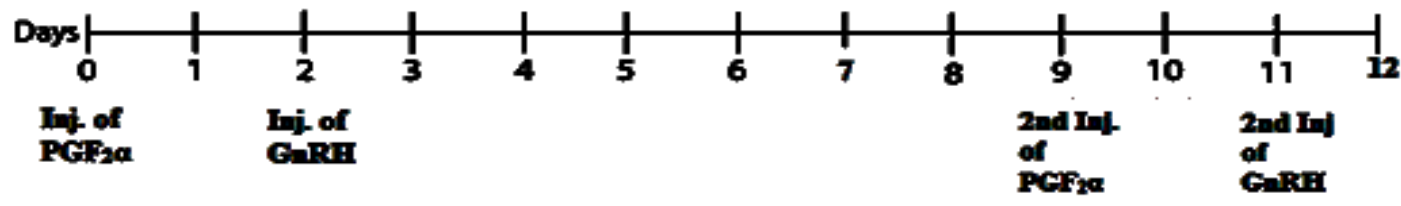

DOUBLE SYNCE PROTOCOL

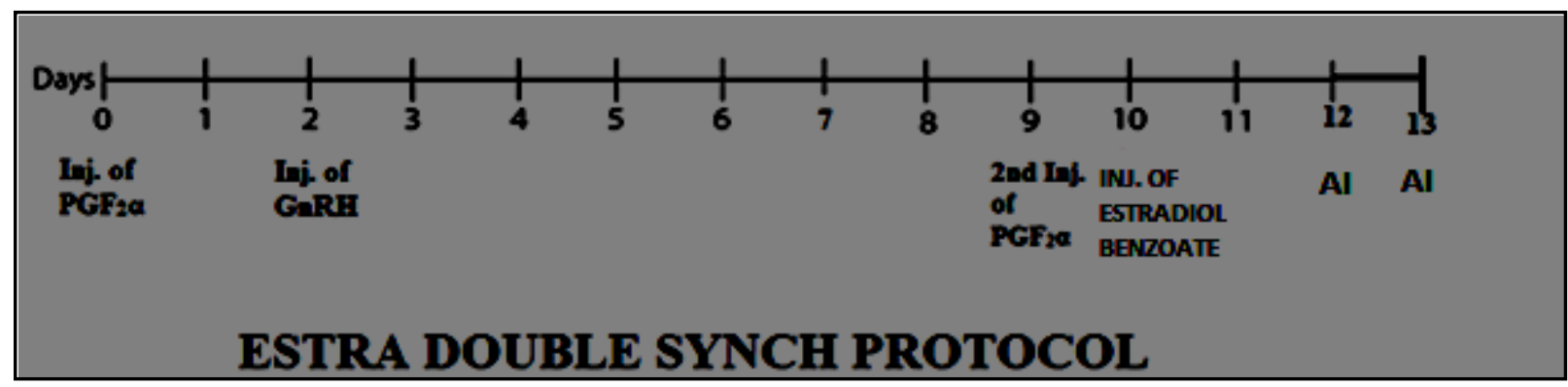

Table.1 Conception rate of repeat breeding animals after various therapeutic Regimen

\begin{tabular}{|c|c|c|c|c|c|c|}
\hline $\begin{array}{l}\text { Treatment groups } \\
\qquad \begin{array}{c}(\mathbf{n}=\mathbf{2 0}) \\
(10 \mathrm{H}+10 \mathrm{C})\end{array}\end{array}$ & $\begin{array}{c}\text { RB } \\
\text { Heifers } \\
\text { concieved }\end{array}$ & $\begin{array}{c}\text { Conception } \\
\text { Rate }(\%)\end{array}$ & $\begin{array}{l}\text { RB Cows } \\
\text { concieved }\end{array}$ & $\begin{array}{c}\text { Conception } \\
\text { Rate }(\%)\end{array}$ & $\begin{array}{c}\text { Total } \\
\text { animals } \\
\text { concieved }\end{array}$ & $\begin{array}{c}\text { Overall } \\
\text { conception } \\
\text { rate }(\%)\end{array}$ \\
\hline Gr I & 1 & 10 & 2 & 20 & $3 / 20$ & 15 \\
\hline Gr II & 4 & 40 & 4 & 40 & $8 / 20$ & 40 \\
\hline Gr III & 6 & 60 & 7 & 70 & $13 / 20$ & 65 \\
\hline Gr IV & 7 & 70 & 7 & 70 & $14 / 20$ & 70 \\
\hline
\end{tabular}

The conception percentage in repeat breeding animals was higher in group IV $(70 \%)$ as compare to group I (15\%) and group II (40\%) which is in accordance with the findings of Mirmahmoudi et al., (2014) who demonstrated the pregnancy rates as $62 \%$ for TAI of cycling buffaloes, $64 \%$ for anestrus buffaloes in Estra doublesynch protocol treated group and $34.5 \%$ for control group. In Estra doublesynch protocol, the total estrogen concentration gradually increased from the day of GnRH administration coinciding with LH peak, and then gradually declined to the basal level until the time of ovulation. Similarly follicle size gradually increased from second $\mathrm{PGF}_{2} \alpha$ injection until ovulation.

The conception rate in repeat breeding animals was higher in both group III (65\%) and group IV (70\%) which is similar to the findings of Das et al., (2016) who found that the hormonal protocol (either doublesynch or estra doublesynch) improved the conception rate of crossbred cows with reproductive disorders by 45 to 60 per cent respectively. The variation may be due to type of reproductive disorders considered for the experiment.

However, the conception rate in repeat breeding animal was higher in group IV $(70 \%)$ than group III (65\%) which corroborates with the findings of Mirmahmoudi and Prakash (2012) who found the pregnancy rates after Estra doublesynch (62.2\%) higher than Doublesynch (58.1\%) protocol in cycling bufffaloes. Similarly, Das et al., (2016) also given similar report after 
experimenting on crossbred cows with various reproductive disorders.

Our result confirms and support that the Doublesynch and Estra doublesynch protocol showing higher conception rate compared to animals subjected to mineral supplementation alone or control group. Hence it can be concluded that the reproductive-disorders in cyclic nonbreeding cattle can be treated effectively by use of both the synch protocol along with mineral supplementation in field condition.

\section{References}

Brunner, M.A. (1984). Dairy integrated reproductive management. Cornell University, IRM-23.

Caraba I. and Velicevici S. (2013). Using Ovsynch protocol versus co synch protocol in dairy cows, Scientific Papers: Animal Science and Biotechnologies, 46(2): 63-65.

Cirit U., Ak K., Ileri I.K. (2007). New stratergies to improve the efficiency of the ovsynch protocol in primiparous dairy cow. Bull Vet. Inst. Pulaway, 51: 47-51.

Das, S., Pradhan, C.R., Mishra, S.K., Swain, R.K., Mishra, P.C., Sahoo, G., Sethy, K. and Mohanty, G.P. (2016). Comparative efficacy of nutritional and hormonal interventions on the reproductive performance of cows. J. of Anim. Nutri. And Feed Tech., 16, 3: 427-438.

Devasena B., Reddy, I.J., Ramana, J.V., Eswara Prasad P. and Rama Prasad J. (2010). Effect of supplementation of area specific mineral mixture on reproductive performance of crossbred cattle: A field study, Indian Journal of Animal Nutrition, 27(3): 265-270.

Fricke P.M., Guenther J.N. and Wiltbank M.C. (1998). Efficacy of decreasing the dose of GnRH used in a protocol for synchronization of ovulation and timed AI in lactating dairy cows. Theriogenology, 50: 1275-1284.

Keskin, A., Yilmazbas-Mecitoglu, G., Gumen, A., Karakaya, E., Darici, R. and Okut, H. (2010). Effect of hCG vs. GnRH at the beginning of the Ovsynch on first ovulation and conception rates in cyclic lactating dairy cows. Theriogenology, 74, 4: 602-607.

Lafi, S.Q., Kaneene, J.B. (1992). Epidemiological and economical study of the repeat breeder syndrome in Michigan dairy cattle. Epidemiological modeling. Prev. Vet. Med., 14: 87-98.

Mihm, M., Curran, N., Hyttel, P., Boland, M.P. and Roche, J.F. (1994). Resumption of meiosis in cattle oocytes from preovulatory follicles with a short and a long duration of dominance. $J$. Reprod. Fertil. Abstr. Ser., 13: 14.

Mirmahmoudi R., Souri M. and Prakash B.S. (2014). Endocrine changes, timing of ovulation, ovarian follicular growth and efficacy of a novel protocol (Estra doublesynch) for synchronization of ovulation and timed artificial insemination in Murrah buffaloes (Bubalus bubalis). Theriogenology, 81(2): 237-242.

Mirmahmoudi, R. and Prakash, B.S. (2012). The endocrine changes, timing of ovulation and efficacy of the Doublesynch protocol in the Murrah Buffaloes. Gen Comp. Endocr., 177: 153-159.

Mohapatra P, Swain RK, Mishra SK, Sahoo G and Rout KK. (2012). Effect of supplementation of area specific mineral mixture on reproductive performance of the cows, Indian Journal of Animal Science, 82(12): 1558-1563.

Ozturk, O.A., Cirit, U., Baran, A., Ak K. (2010). Is Doublesynch protocol a new alternative for timed artificial 
insemination in anestrous dairy cows. Theriogenology, 73: 568-76.

Ramakrishnan, A., Dhami, A.J., Naikoo, M., Parmar, B.C. and Divekar, B.S. (2012). Estrus induction and fertility response in postpartum anestrus Gir cows. Indian J. of Anim. Reprod., 33 (1): 37-42.
Thatcher W.W., Drost, M., Savio, J.D., Macmillan, K.L., Entwistle, K.W. and Schmitt, E.J. (1993). New clinical uses of $\mathrm{GnRH}$ and its analogues in cattle. Anim. Reprod. Sci., 33: 27-49.

\section{How to cite this article:}

Harichandan, P.P., A.K. Barik, P.C. Mishra, B.K. Patra, B. Jena, S.K. Mishra and Kundu, A.K. 2018. Efficacy of Doublesynch and Estra Doublesynch on Conception Rate of Cyclic Non breeding Cattle. Int.J.Curr.Microbiol.App.Sci. 7(04): 1025-1030.

doi: https://doi.org/10.20546/ijcmas.2018.704.112 